\title{
Kidney length, a visceral parameter predicts foetal age between 24 to 40 weeks of gestation
}

\section{Sunanda Bharatnur*, Samantha Dawson, Shripad Hebbar}

Department of Obstetrics and Gynecology, KMC Manipal MAHE Manipal, Karnataka, India

Received: 28 October 2018

Accepted: 13 December 2018

\section{*Correspondence:}

Dr. Sunanda Bharatnur,

E-mail: sunanda.somu77@gmail.com

Copyright: (C) the author(s), publisher and licensee Medip Academy. This is an open-access article distributed under the terms of the Creative Commons Attribution Non-Commercial License, which permits unrestricted non-commercial use, distribution, and reproduction in any medium, provided the original work is properly cited.

\begin{abstract}
Background: Accurate estimation of gestational age is important in providing appropriate antenatal care. Recent evidence suggests that weightage should also be given to kidney length in addition to standard biometric parameters in determining the duration of pregnancy by ultrasound.

Methods: In a single centre, prospective cross-sectional study was done in 120 pregnant women. In addition to standard biometric parameters, kidney length was also measured between 24 to 40 weeks at two-week intervals. A total of 240 renal vertical measurements were done and average of right and left renal lengths was taken as a final kidney length. Descriptive analysis was carried out to find the mean and standard deviations for each variable. Regression analysis was carried for each variable either singly or in combinations and Pearson regression coefficients was used to find the association between gestational age and various foetal parameters and to determine which of the regression model gives the best fit for prediction of gestational age.

Results: Foetal kidney length progressively increased throughout the gestation (from $23.2 \mathrm{~mm}$ at 24 weeks to 40.1 $\mathrm{mm}$ at 40 weeks). The regression formula using only kidney length as an independent variable (gestational age $=2.195 \pm 0.942 \mathrm{X}$ kidney length) had high degree of correlation (R2 0.97, $\mathrm{p}<0.001$, SE of prediction 4.7 \pm 3.9 ), which was superior to other prediction models using standard biometric parameters. In multiple regression models using several conventional parameters, when femur length was added in a stepwise manner, there was significant improvement in forecasting gestational age.

Conclusions: Present study showed that foetal kidney length is a reliable indicator of gestational age between 24 to 40 weeks of pregnancy and may be of utility in pregnancies with wrong dates, non-availability of dating scan and women who have conceived during lactational period.
\end{abstract}

Keywords: Foetal kidney length, Gestational age, Ultrasound

\section{INTRODUCTION}

It is well-known fact that precise estimation of gestational age is of utmost importance in modern obstetrics, especially in situation where dating scans are not available, conception occurs during lactational period or the woman has irregular menstrual cycles. ${ }^{1}$ In case the gestational age is underestimated, it results in post maturity syndrome along with its inherent complications and an overestimated results leads to leads to iatrogenic prematurity with neonatal complications related to preterm birth. $^{2}$

In managing post term pregnancies, outcome of labour induction is dependent upon accurate knowledge of foetal age as too early induction is associated with high failure rates and increased operative interventions. ${ }^{3}$ Even in the early third trimester correct information about the 
duration of pregnancy is very crucial to decide about antenatal steroid prophylaxis for foetal lung maturation. ${ }^{4}$

In last three decades there has been a tremendous development in ultrasound technology and today it is near impossible to practice obstetrics without ultrasound. ${ }^{5}$

One of the essential components of diagnostic obstetric ultrasound is estimation of gestational age by using various foetal biometric parameters such as biparietal diameter (BPD), head circumference (HC), abdominal circumference (AC) and femur length (FL). ${ }^{6}$

In current scenario all ultrasound machines available in India have inbuilt formulae to calculate gestational age based on foetal biometric variables.

However certain obstetric disorders such as multi-foetal gestation, oligoamnios, malpresentations such as breech and face presentations, foetal growth restriction and maternal obesity may affect routine standard biometric parameters when pregnancy is close to term. ${ }^{7}$

There are various other alternative parameter to measure fetal gestational age estimation compared to conventional ultrasound foetal biometry like trans-cerebellar diameter, orbital diameter, foetal hard palate, clavicular length and foot length. ${ }^{8-12}$

These parameters have excellent performance in the second trimester of pregnancy, but lack in their efficiency as the gestation progresses. ${ }^{13}$ Measuring these parameters require expertise and experience.

There is a need for developing a method of ultrasound assessment of gestational age which is simple to image, user friendly and has least inter-observer and intraobserver variations. ${ }^{14}$

Foetal parameters should not be influenced by errors. Imaging of foetal abdomen is relatively easy to measure vertical length of the kidney in any planes.

It is interesting to note that disorders of the foetal growth, both small and large for gestational age predominantly affect only antero-posterior and transverse diameters of foetal kidney, but not its length. ${ }^{15}$

Assigning the correct gestational age in growth restricted foetus (FGR) possess problem, as the major biometric parameters do not correspond to each other, in particular the abdominal circumference.

It is observed that the length of the foetal kidney is not affected in FGR babies. A recent systematic review has highlighted the role of foetal kidney length in determining gestational age. ${ }^{16}$ The present study has focus on usefulness of foetal kidney length $(\mathrm{KL})$ measurements beginning from 24th week of gestation till term and compares with traditionally used biometric parameters, i.e., BPD, HC, AC and FL.

\section{METHODS}

This study is an institution based prospective crosssectional study conducted on singleton pregnant women from 24 weeks to till term. The study was carried out over a period of 14 months (Feb 2016 to April 2017). All the participating women gave informed consent. Gestational age was assigned by reliable last menstrual period, first trimester CRL (Crown Rump Length).

\section{Exclusion criteria}

- Anomalous foetuses

- Multifoetal gestation

- Oligoamnios

- Severe foetal growth restriction.

Sample size was 120 meeting the regression analysis for independent variables (BPD, HC, AC, and FL and $\mathrm{KL}$ ) and a dependent variable (GA-Gestational Age). Fetal biometric measurements were done fortnightly till 40 weeks using GE Voluson P8 machine with a $3.5 \mathrm{MHz}$ convex probe. Kidney Length was scanned first locating the foetal abdomen in transverse section at the level of stomach and thereafter rotating the probe to 90 degree to obtain the foetal Kidney in longitudinal plane.

After excluding the adrenal glands, distance between upper and lower pole of the both the kidneys were measured and average distance was considered for analysis. SPSS (Statistical Package for Social Sciences, Chicago, version 16) package is used for descriptive analysis. For regression analysis, a free Microsoft Excel add-in (regress it) was used. Pearson regression coefficients were used to analyze foetal parameter.

\section{RESULTS}

A total of 240 kidneys (right and left) were measured in a cross-sectional population of 120 pregnant women at different gestational ages ranging from 24 to 40 weeks of gestation at two-week interval. Both kidneys were measured in each patient and their mean and standard deviation was calculated. Mean and SD were also calculated for other biometric parameters.

Table 1 highlights that all the biometric parameters recorded steady increase as the gestation advanced. Visually the kidney length ( $\mathrm{mm}$ ) was equal to gestational age in weeks.

Table 2 shows accuracy of prediction of gestational age by using five biometric parameters individually. Regression equations have been obtained for all parameters. It can be seen that BPD predicted GA within 12.6 days, whereas it was only 4.7 days for KL. 
Table 1: Changes in biometric parameters with gestation. Values ( $\mathrm{mm})$ are expressed in Mean \pm SD.

\begin{tabular}{|c|c|c|c|c|c|c|}
\hline GA & n & BPD & $\mathrm{HC}$ & $\mathbf{A C}$ & FL & KL \\
\hline 24 & 14 & $59.7 \pm 3.8$ & $208.3 \pm 9.5$ & $182.5 \pm 21.6$ & $40.3 \pm 2.8$ & $23.2 \pm 1.1$ \\
\hline 26 & 15 & $64.8 \pm 3.7$ & $233.8 \pm 12$ & $203.9 \pm 12.9$ & $45 \pm 3.7$ & $25.5 \pm 1.1$ \\
\hline 28 & 14 & $72.6 \pm 2.7$ & $267.7 \pm 12.7$ & $234.2 \pm 17.5$ & $50.3 \pm 2.8$ & $27.8 \pm 0.7$ \\
\hline 30 & 15 & $78.2 \pm 3.6$ & $280.3 \pm 14.5$ & $252.4 \pm 9.4$ & $54.8 \pm 3$ & $29.6 \pm 0.6$ \\
\hline 32 & 13 & $82.9 \pm 2.5$ & $291.8 \pm 8.2$ & $274.5 \pm 11.7$ & $58.8 \pm 2.2$ & $31.6 \pm 0.8$ \\
\hline 34 & 12 & $87 \pm 5.1$ & $301.6 \pm 12.4$ & $283.2 \pm 14.1$ & $62.2 \pm 2.8$ & $33.7 \pm 0.6$ \\
\hline 36 & 12 & $87.6 \pm 4.1$ & $311 \pm 12.8$ & $291.6 \pm 12$ & $65 \pm 1.9$ & $35.8 \pm 0.7$ \\
\hline 38 & 12 & $91.6 \pm 3.6$ & $319.8 \pm 7.5$ & $313.6 \pm 13.5$ & $68.6 \pm 3.7$ & $37.4 \pm 0.5$ \\
\hline 40 & 13 & $93.6 \pm 3.3$ & $321.9 \pm 14$ & $334 \pm 26.3$ & $70.8 \pm 3.1$ & $40.1 \pm 1.7$ \\
\hline
\end{tabular}

$\mathrm{n}$ is the number of women examined at different gestational ages

Table 2: Regression equations of five major biometric variables and their regression coefficients.

\begin{tabular}{|l|l|l|l|l|l|}
\hline Parameter & Regression equation & Accuracy of prediction (days) & R-squared & Adj.R Sqr** \\
\hline BPD & GA $=-0.580+0.408^{*} \mathrm{BPD}$ & $12.6 \pm 8.9$ & 0.87 & 0.869 \\
\hline $\mathrm{HC}$ & $\mathrm{GA}=-2.180+0.121 * \mathrm{HC}$ & $12.1 \pm 8.5$ & 0.833 & 0.831 \\
\hline $\mathrm{AC}$ & $\mathrm{GA}=6.263+0.098^{*} \mathrm{AC}$ & $9.9 \pm 7.5$ & 0.883 & 0.882 \\
\hline $\mathrm{FL}$ & $\mathrm{GA}=4.726+0.475 * \mathrm{FL}$ & $8.6 \pm 6.6$ & 0.911 & 0.911 \\
\hline $\mathrm{KL}$ & $\mathrm{GA}=2.195+0.942 * \mathrm{KL}$ & $4.7 \pm 3.9$ & 0.972 & 0.971 \\
\hline
\end{tabular}

*Adj. R Sqr-adjusted R square

KL relates to GA linearly as shown by Pearson regression coefficients (both R Square and Adjusted R Squares0.972 and 0.971 respectively).

Figure 1 to 5 show regression graphs along with the predicting equations and regression lines. Both upper and lower 95th regression lines are also shown. Analysis of data points in scattered diagram show KL measurements are close to the regression line compared to other four parameters.

Figure 1 to 5 show regression graphs along with the predicting equations and regression lines. Both upper 95th and lower 95th regression lines are also shown. Analysis of data points in scattered diagram show that $\mathrm{KL}$ measurements were close to the regression line compared to other four parameters.

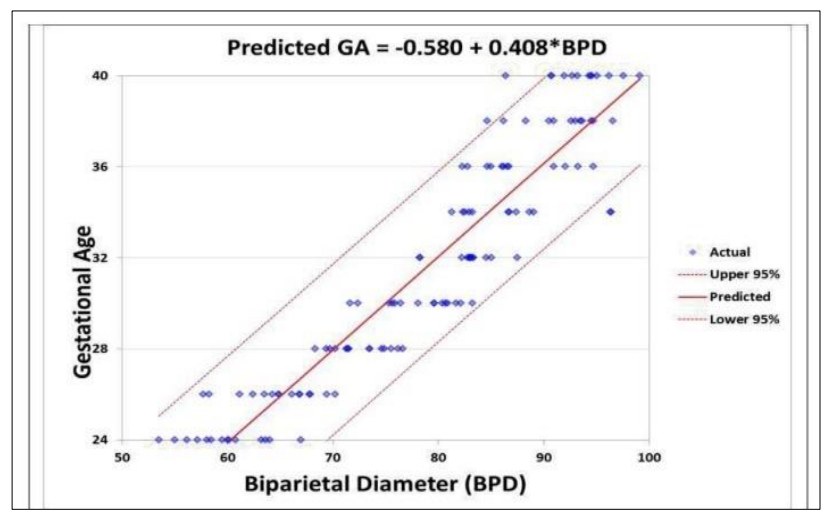

Figure 1: Relationship between BPD and GA.

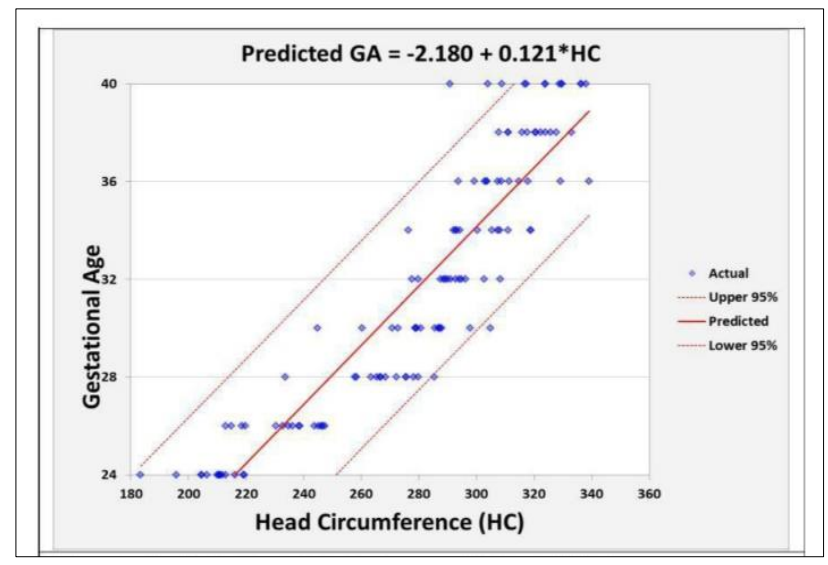

Figure 2: Relationship between $\mathrm{HC}$ and GA.

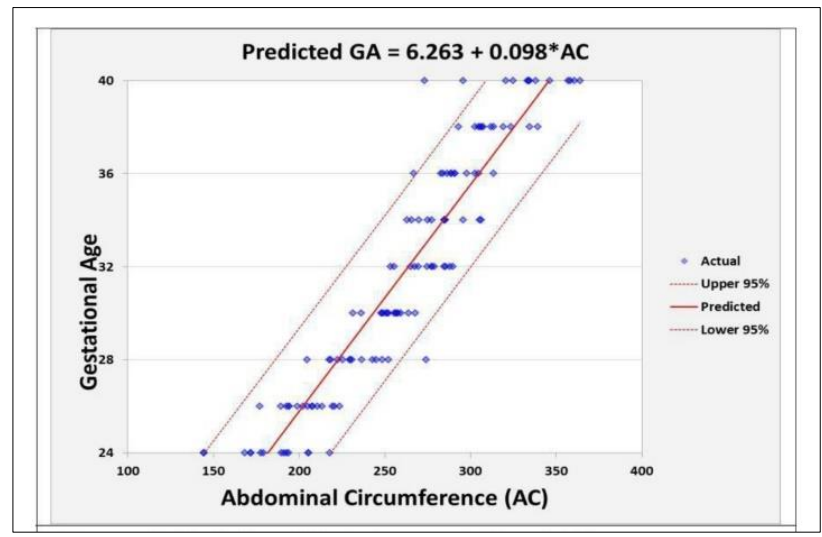

Figure 3: Relationship between AC and GA. 


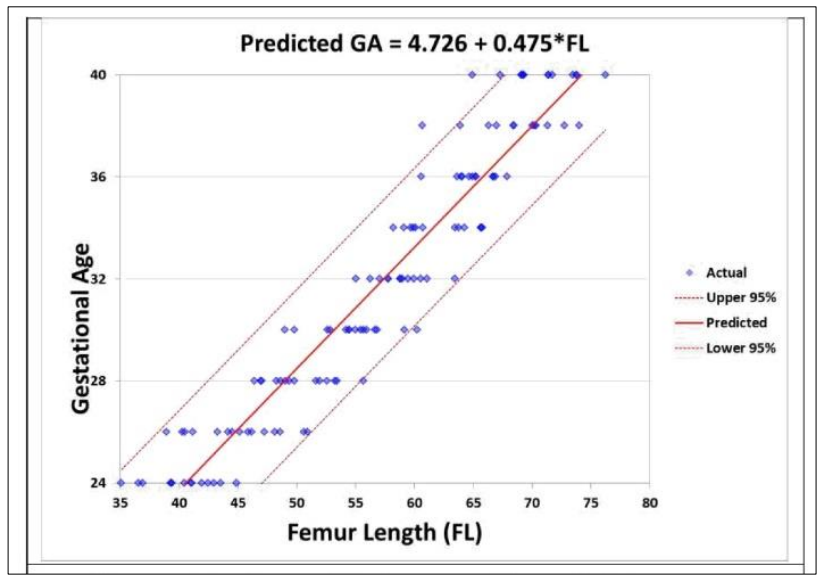

Figure 4: Relationship between FL and GA.

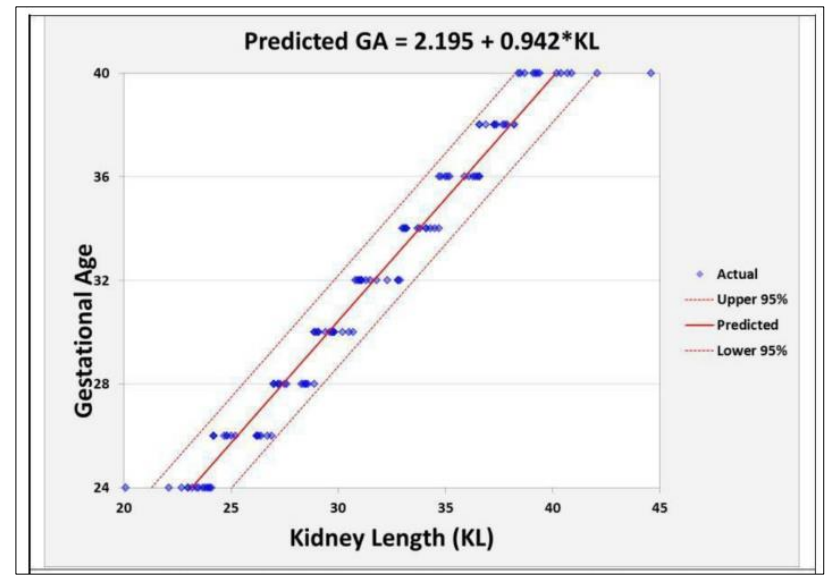

Figure 5: Relationship between KL and GA.

Table 3: In-depth regression analysis for independent variables.

\begin{tabular}{|c|c|c|c|c|c|c|c|c|c|c|c|c|}
\hline \multirow{3}{*}{ Parameter } & \multirow{2}{*}{\multicolumn{2}{|c|}{ Intercept }} & \multirow{2}{*}{\multicolumn{3}{|c|}{ Slope }} & \multicolumn{5}{|c|}{$95 \%$ Confidence Interval } & \multirow{2}{*}{ t statistics } & \multirow{2}{*}{$\mathbf{P}$ value } \\
\hline & & & & & & \multicolumn{2}{|c|}{ Intercept } & \multicolumn{3}{|c|}{ Slope } & & \\
\hline & $\mathbf{E}$ & SE & $\mathbf{E}$ & SE & LB & UB & LB & UB & $\mathbf{I}$ & $\mathbf{S}$ & $\mathbf{I}$ & $\mathbf{S}$ \\
\hline BPD & -0.58 & 1.16 & 0.41 & 0.02 & -2.88 & 1.72 & 0.38 & 0.44 & -0.5 & 28.1 & 0.62 & $<0.001$ \\
\hline $\mathrm{HC}$ & -2.18 & 1.41 & 0.12 & 0.01 & -4.97 & 0.61 & 0.11 & 0.13 & -1.55 & 24.24 & 0.13 & $<0.001$ \\
\hline $\mathrm{AC}$ & 6.26 & 0.87 & 0.98 & 0.1 & 4.55 & 7.98 & 0.09 & 0.1 & 7.2 & 29.81 & $<0.01$ & $<0.001$ \\
\hline FL & 4.72 & 0.78 & 0.48 & 0.02 & 3.170 & 6.28 & 0.45 & 0.502 & 6.01 & 34.85 & $<0.01$ & $<0.001$ \\
\hline KL & 2.2 & 0.47 & 0.94 & 0.01 & 1.27 & 3.13 & 0.91 & 0.97 & 4.67 & 63.64 & $<0.01$ & $<0.0001$ \\
\hline
\end{tabular}

E: Estimate, SE: Standard error, LB: Lower bound, UB: Upper bound, I: Intercept, S: Slope

Table 4: Various combinations of KL with other biometric variables and their regression performance.

\begin{tabular}{|c|c|c|c|c|}
\hline \multirow[t]{2}{*}{ Parameters } & \multirow[t]{2}{*}{ Regression equations } & $\mathbf{R}$ & $\begin{array}{l}\text { Adj. } \\
\text { R Sq }\end{array}$ & \multirow{2}{*}{$\begin{array}{l}\text { SE } \\
\text { Reg }\end{array}$} \\
\hline & & Square & $\mathbf{r}$ & \\
\hline BPD & $\mathrm{GA}=-0.580+0.408(\mathrm{BPD})$ & 0.87 & 0.87 & 1.88 \\
\hline $\mathrm{BPD}, \mathrm{KL}$ & $\mathrm{GA}=0.874+0.081(\mathrm{BPD})+0.781(\mathrm{KL})$ & 0.98 & 0.98 & 0.79 \\
\hline $\mathrm{BPD}, \mathrm{HC}$ & $\mathrm{GA}=-2.81+0.257(\mathrm{BPD})+0.0504(\mathrm{HC})$ & 0.9 & 0.89 & 1.68 \\
\hline $\mathrm{BPD}, \mathrm{HC}, \mathrm{KL}$ & $\mathrm{GA}=0.439+0.067(\mathrm{BPD})+0.0086(\mathrm{HC})+0.752(\mathrm{KL})$ & 0.98 & 0.98 & 0.79 \\
\hline $\mathrm{BPD}, \mathrm{HC}, \mathrm{AC}$ & $\mathrm{GA}=0.055+0.143(\mathrm{BPD})+0.0295(\mathrm{HC})+0.0046(\mathrm{AC})$ & 0.93 & 0.92 & 1.42 \\
\hline $\mathrm{BPD}, \mathrm{HC}, \mathrm{AC}, \mathrm{KL}$ & $\mathrm{GA}=0.546+0.064(\mathrm{BPD})+0.0082(\mathrm{HC})+0.0028(\mathrm{AC})+0.735(\mathrm{KL})$ & 0.98 & 0.98 & 0.79 \\
\hline $\mathrm{BPD}, \mathrm{HC}, \mathrm{AC}, \mathrm{FL}$ & $\mathrm{GA}=1.434+0.091(\mathrm{BPD})+0.0125(\mathrm{HC})+0.0028(\mathrm{AC})+0.214(\mathrm{FL})$ & 0.95 & 0.95 & 1.21 \\
\hline $\mathrm{BPD}, \mathrm{HC}, \mathrm{AC}, \mathrm{FL}, \mathrm{KL}$ & $\mathrm{GA}=0.982+0.054(\mathrm{BPD})+0.0044(\mathrm{HC})+0.001(\mathrm{AC})+0.076(\mathrm{FL})+0.659(\mathrm{KL})$ & 0.99 & 0.98 & 0.75 \\
\hline
\end{tabular}

Adj. R Sqr: Adjusted R Square, SE Reg: Standard Error of Regression

Table 3 shows in-depth regression analysis of both intercept and slopes of regression equations along with their $95 \%$ confidence interval (CI) and p values. It is seen that FL has statistically significant relation with GA in relation to both intercept and slope $(\mathrm{p}<0.01$ and $\mathrm{p}<0.001$, t-statistics 6.01 and 34.9). Even though other parameters showed significant correlation, but not as superior as KL. Table 4 shows regression performance of $\mathrm{KL}$ when combined with other variables by stepwise addition. It can be seen addition of KL to various standard biometric parameters enhances their diagnostic accuracy as seen by progressive improvement in regression coefficients and decreasing standard errors of regression. The best prediction model with least error was combination of BPD, HC, and AC, FL and KL (R Square 0.99, Adj R Square 0.98 and Standard Error 0.75).

Thus, all the result favour KL as a strong predictor of GA either single or in combinations with other biometric parameter. Figure 5 it is evident that the slope of $\mathrm{KL}$ is 0.942 and it is close to 1 which indicates that the gestational age in week equals to kidney length in $\mathrm{mm}$. 


\section{DISCUSSION}

In developing countries like India many times, researches confront pregnant women in late gestation and estimation of EDD is often is difficult in the absence of reliable menstrual history and dating scan. In such cases ultrasound becomes handy as gestational age can be estimated using foetal biometry. However, foetal age calculation requires multiple biometric parameters such as BPD, HC, AC, FL, unless inbuilt functions are available in the ultrasound machine. Like clinical symphysiofundal height which corresponds to duration of pregnancy, there is a need of an ultrasound parameter which can determine the gestational age at a glance. This measurement should be simple to perform, observer independent and easily reproducible. Transcerebellar diameter and foetal kidney length are among such parameters. A frequently quoted rule of thumb is that "kidney length in $\mathrm{mm}$ approximates gestational age in weeks". The specialty of kidney length is its echogenic pattern which changes as pregnancy advances. The perinephric fat which surrounds the kidney has characteristic increased echogenicity which delineates the kidney from surrounding tissues. ${ }^{17}$ Another advantage of renal vertical length measurement is that it does not change in intrauterine growth restriction and small for gestational age foetuses. ${ }^{18}$ However, the same is not true with antero-posterior and transverse diameter, but the degree of changes that manifest with foetal nutritional problems is yet to be explored. ${ }^{19}$ A recent study looked at the value of 3 dimensional measurements of renal parameters in predicting birth weight at the time of delivery. ${ }^{20}$ Overall study of foetal kidneys appears to be interesting and may have utility value in high risk pregnancy management. Table 5 shows comparative values of foetal kidney length across gestation. Konje JC et al studied foetal kidney length from 24 weeks till 38 weeks in 73 uncomplicated pregnancies at two-week intervals. Other important biometric variables were also taken into consideration. ${ }^{21}$ They used stepwise regression model including BPD, HC, AC, FL and $\mathrm{KL}$ which predicted gestational age precisely within range of \pm 8.48 days. A model including kidney length, biparietal diameter, and head circumference and femur length accurately predicted gestational age with a standard error of \pm 8.57 days. They recommended that KL should be routinely incorporated for dating of pregnancy after 24 weeks of gestation, especially when measurements of the BPD and HC are difficult. Kansaria and Parulekar studied the foetal kidney length along with the other major biometric variables from 22 week to 38 weeks of pregnancy and found that foetal kidney grows at $0.85 \mathrm{~mm}$ per week. ${ }^{22}$ They demonstrated that predictive model comprising of kidney length could estimate the expected date of delivery within 9.17 days and was better than models which incorporated BPD, HC, AC and FL.

Table 5. Comparative study of kidney length by various authors.

\begin{tabular}{|c|c|c|c|c|c|}
\hline Gest & Konje JC et al ${ }^{21}$ & Kansaria et $a^{22}$ & Kumar $\mathrm{M}$ et $\mathrm{al}^{23}$ & Peter $\mathbf{M}$ et $\mathrm{al}^{24}$ & Present study \\
\hline \multicolumn{6}{|l|}{ Age } \\
\hline 24 & $24.2 \pm 1.2$ & $23.87 \pm 1.17$ & $21.6 \pm 1.7$ & $22.5 \pm 0.07$ & $23.2 \pm 1.1$ \\
\hline 26 & $26.3 \pm 1.9$ & $25.23 \pm 1.18$ & $26.3 \pm 1.14$ & $26.2 \pm 0.10$ & $25.5 \pm 1.1$ \\
\hline 28 & $29 \pm 2.2$ & $26.98 \pm 1.06$ & $29.8 \pm 2.24$ & $28 \pm 0.08$ & $27.8 \pm 0.7$ \\
\hline 30 & $30.9 \pm 3.2$ & $29.03 \pm 1.32$ & $34.3 \pm 1.24$ & $30.2 \pm 0.09$ & $29.6 \pm 0.6$ \\
\hline 32 & $33.2 \pm 4.5$ & $30.8 \pm 1.53$ & $36.2 \pm 0.7$ & $31.2 \pm 0.04$ & $31.6 \pm 0.8$ \\
\hline 34 & $35 \pm 3.6$ & $32.51 \pm 1.38$ & $37.2 \pm 1.04$ & $33.2 \pm 0.04$ & $33.7 \pm 0.6$ \\
\hline 36 & $38.2 \pm 4.2$ & $34.26 \pm 1.41$ & $38.9 \pm 1.53$ & $35.7 \pm 0.13$ & $35.8 \pm 0.7$ \\
\hline 38 & $40.1 \pm 2.4$ & $36.25 \pm 1.7$ & $40.4 \pm 1.71$ & $37.3 \pm 0.07$ & $37.4 \pm 0.5$ \\
\hline 40 & NA & NA & NA & $37.9 \pm 0.13$ & $40.1 \pm 1.7$ \\
\hline
\end{tabular}

NA: Not Available

Kumar $\mathrm{M}$ et al studied FL and KL between 18 to 38 weeks of gestation in 119 women with uncomplicated pregnancies. ${ }^{23}$ They were able to image foetal kidney as early as 18 weeks with mean length of $12 \pm 1.3 \mathrm{~mm}$. This increased to $40.4 \pm 1.7 \mathrm{~mm}$ at term (38 weeks). The standard error for prediction of expected date of delivery was \pm 8.04 days and was better compared to BPD $( \pm 8.75$ days). Peter $M$ et al conducted a prospective crosssectional study on fetal kidney length after 24 weeks of gestations. $^{24}$ They demonstrated linear relationship between FL and GA and standard error of prediction was only \pm 9.04 days when only FL was used and in combination with other biometric indices it could be further reduced to \pm 8.3 days. In our opinion kidney length being such a useful parameter should be extended to complicated pregnancies, such as multiple pregnancies, pregnancies with complications such as preeclampsia, gestational diabetes etc. The sophisticated ultrasound machine may overcome the technical difficulties due to maternal obesity and other causes of poor ultrasound window. Multicentric trials, larger sample sizes will definitely help us to establish national standards for fetal kidney length in Indian women at various periods of gestation. 


\section{CONCLUSION}

India has significantly higher population of rural women who do not have concept of early first trimester registration and they seek pre-pregnancy care late in gestation. Many women do not remember their LMP and difficulties may arise in planning for delivery unless they are subjected to ultrasound examination. It is recommended that the sonologist performing the scan, should comment on fetal kidney length in addition to standard biometric parameter. The ultrasound machine should be incorporated with defined formula for KL, so that gestational age calculated along with other standard biometric parameters.

Funding: No funding sources Conflict of interest: None declared

Ethical approval: The study was approved by the Institutional Ethics Committee

\section{REFERENCES}

1. Jehan I, Zaidi S, Rizvi S, et al. Dating gestational age by last menstrual period, symphysis-fundal height, and ultrasound in urban Pakistan. Int J Gynaecol Obstet. 2010;110(3):231-4.

2. Zador IE, Hertz RH, Sokol RJ, Hirsch VJ. Sources of error in the estimation of fetal gestational age. Am J Obstet Gynecol. 1980;138(3):344-5.

3. Butt K, Lim K. Determination of gestational age by ultrasound. J Obstet Gynaecol Can. 2014;36(2):171-81.

4. Murphy KE, Willan AR, Hannah ME, et al. Effect of antenatal corticosteroids on fetal growth and gestational age at birth. Obstet Gynecol. 2012;119(5):917-23.

5. Filkins K, Koos BJ. Ultrasound and fetal diagnosis. Curr Opin Obstet Gynecol. 2005;17(2):185-95.

6. March MI, Warsof SL, Chauhan SP. Fetal biometry: relevance in obstetrical practice. Clin Obstet Gynecol. 2012;55(1):281-7.

7. Buscicchio G, Milite V, D’Emidio L, Giorlandino M, Cavaliere A, Padula F, et al. Analysis of fetal biometric measurements in the last 30 years. J Prenat Med. 2008;2(1):11-3.

8. Orji MO, Adeyekun AA. Ultrasound estimation of foetal gestational age by transcerebellar diameter in healthy pregnant nigerian women. West Afr J Med. 2014;33(1):61-7.

9. Rosati P, Bartolozzi F, Guariglia L. Reference values of fetal orbital measurements by transvaginal scan in early pregnancy. Prenat Diagn. 2002;22(10):851-5.

10. Sherer DM, Sokolovski M, Santoso PG, Dalloul M, Abulafia O. Nomograms of sonographic measurements throughout gestation of the fetal hard palate width, length and area. Ultrasound Obstet Gynecol. 2004;24(1):35-41.

11. Yarkoni S, Schmidt W, Jeanty P, Reece EA, Hobbins JC. Clavicular measurement: a new biometric parameter for fetal evaluation. J Ultrasound Med. 1985;4(9):46770.

12. Shripad Hebbar, Kopal S, Prashant Adiga, Lavanya Rai. Fetal foot length throughout gestation: a nomogram. Sri Lanka Journal of Obstetrics and Gynaecology. 2013;35(2):58-6

13. Tarca AL, Hernandez-Andrade E, Ahn H, Garcia M, Xu Z, Korzeniewski SJ, et al. Single and Serial Fetal Biometry to Detect Preterm and Term Small- and Large-for-Gestational-Age Neonates: A Longitudinal Cohort Study. PLoS ONE. 2016;11(11):e0164161.

14. Papageorghiou AT, Kemp B, Stones W, Ohuma EO, Kennedy SH, Purwar M, et al. Ultrasound-based gestational-age estimation in late pregnancy. Ultrasound Obstet Gynecol. 2016;48(6):719-26.

15. Ugur MG, Mustafa A, Ozcan HC, Tepe NB, Kurt H, Akcil E, et al. Fetal kidney length as a useful adjunct parameter for better determination of gestational age. Saudi Med J. 2016;37(5):533-7.

16. Brennan $S$, Watson $D$, Rudd D, Schneider $M$, Kandasamy Y. Evaluation of fetal kidney growth using ultrasound: A systematic review. Eur J Radiol. 2017;96:55-64.

17. Sato A, Yamaguchi Y, Liou SM, Sato M, Suzuki M. Growth of fetal kidney assessed by real time ultrasound. Eur Urol. 1990;17(1):62-5.

18. Konje JC, Abrams KR, Bell SC, Taylor DJ. Determination of gestational age after 24th week of gestation from fetal kidney length measurements. Ultrasound Obstet Gynecol 2002;19(6):592-7.

19. Latini G, De mitri B, Del vecchio A, Chitano G, De felice C, Zetterström R. Foetal growth of kidneys, liver and spleen in intrauterine growth restriction: "programming" causing "metabolic syndrome" in adult age. Acta Paediatr. 2004;93(12):1635-9.

20. Mishra K, Datta V, Aarushi A, Kaur narula M, Iyer RS, Nangia S. The Association between Weight for Gestational Age and Kidney Volume: A Study in Newborns in India. Iran J Pediatr. 2014;24(1):93-9.

21. Konje JC, Abrams KR, Bell SC, Taylor DJ. Determination of gestational age after the 24th week of gestation from fetal kidney length measurements. Ultrasound Obstet Gynecol. 2002;19(6):592-7.

22. Kansaria JJ, Parulekar SV. Nomogram for fetal kidney length. Bombay Hosp J. 2009;51(2):155-62.

23. Kumar M, Lalwani R, Babu R, Aneja S, Malik A. Ultrasonographic estimation of fetal gestational age by fetal kidney length. J Anat Soc India. 2013;62:33-6.

24. Peter M, Nayak AK, Giri PP, Jain MK. Fetal kidney length as a parameter for determination of gestational age from 20th week to term in healthy women with uncomplicated pregnancy. Int $\mathbf{J}$ Res Med Sci 2017;5(5):1869-73.

Cite this article as: Bharatnur S, Dawson S, Hebbar S. Kidney length, a visceral parameter predicts foetal age between 24 to 40 weeks of gestation. Int $\mathbf{J}$ Reprod Contracept Obstet Gynecol 2019;8:492-7. 